\title{
TUBERCULOSIS OF THE STOMACH WITH EXTENSIVE TUBERCULOUS LYMPHANGITIS.*
}

\author{
KAETHE W. DEWEY. \\ (From the Pathological Laboratory of Rush Medical College, Chicago.)
}

In most of the articles on tuberculosis of the stomach, two forms, the ulcerative and the hematogenous miliary, are discussed. A third form, the tuberculous lymphangitis, frequently met with in the intestine, is mentioned in few and then only incidentally to accounts of the ulcerative type of lesion. That such a lesion does occur in the stomach and that it may possess features distinct and unlike either of the two varieties, is borne out by the conditions described in the following account.

It concerns a laboring man, 45 years old. The anatomic diagnosis was ulcerative tuberculosis of both apices, and tuberculous bronchopneumonia; caseous tuberculosis of the tracheobronchial lymph glands; disseminated nodular tuberculosis of the inner coat of the stomach; ulcerative tuberculous colitis; emaciation and anemia; brown atrophy of the heart; external fibrous pericarditis; passive hyperemia and atrophy of the liver; bilateral obliterative pleuritis; fibrous adhesions between the descending duodenum and the under surface of the liver. The emaciation was extreme. The body, which was of average height, weighed 64 pounds. The upper arm could be spanned by the thumb and ring finger of one hand, the greatest circumference of the thigh was $27.5 \mathrm{~cm}$.

The tuberculosis of the stomach has formed numerous rather firm elevations of the lining, averaging two to four millimeters in height, on the posterior and anterior wall, but chiefly on the posterior along the lesser curvature (see Fig. I). They are reddish, from a few millimeters to one centimeter in length, many of them rather oblong. In one or two places there are suggestions of superficial erosion caused possibly by rough handling in removal. Some of these ridges are two to three centimeters in length and continuous with elevations which are seen and felt externally.

The tuberculous colitis consists of four large ulcers with rounded regions of thickening similar to those observed in the stomach.

The lesions in the stomach are seen very distinctly, especially by holding the specimen against the light, when at once a certain definiteness of grouping and distribution is apparent. In order to ascertain the relationship of these lesions, the stomach after being made still more translucent by museum fluids was examined by transmitted light and the general correspondence in direction and location between the ridges and blood vessels is illustrated by Fig. 2. The ridges follow the course of the lymph channels as they are described and illustrated by Sappey. ${ }^{\mathrm{r}}$ Cunéo

* Received for publication February 4, I9r3.

I Analomie, Physiologie, Pathologie des vaisseaux lymphatiques, Paris, 1874 . 
and Delamare, ${ }^{2}$ Poirier and Charpy, ${ }^{2}$ Most, ${ }^{3}$ Jamieson and Dobson ${ }^{4}$ (see Fig. 3 ), and: Comolli, 5

It is apparent that the ridges are arranged chiefly toward and along the lesse. curvature, involving the coronary group of lymphatics. The splenic group is represented to some extent, while the hepatic or right gastro-epiploic group is scarcely in evidence.

The tuberculous nature as well as the relation to the lymph channels of these

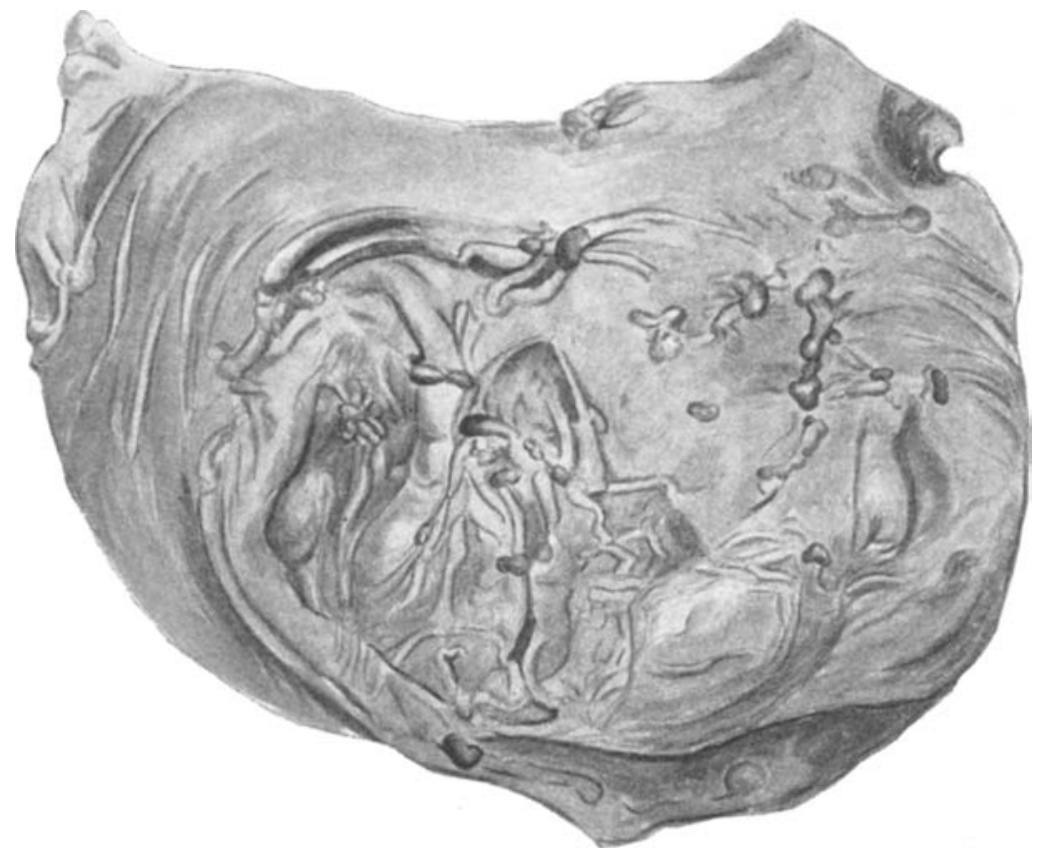

Fic: I.-The ridges and nodular or polypous elevations are grouped chiefly about the lesser curvature. See Fig. 2.

lesions was confirmed by the microscopic examination. Tubercle bacilli are present in large numbers, contrary to the usual reports dealing with tuberculosis of the stomach.

In all respects the structure is typical of tuberculous lesions. Giant cells are found in nearly every section. The infiltration is enormous in those portions where the mucosa is raised to form the ridges; it is especially dense in the mucosa itself where it reaches very close to the surface. Rows of lymphocytes extend along the muscularis mucosae and in the submucosa. In many places they are found just without thin-

s Jour. de l'anat. et physiol., Igoo, 36, p. 393.

- Traite de l'anatomie humaine, Paris, Igor, 2; also in English as Special Study of the Lymphatics in Different Parts of the Body, by Poirier and Cunéo, Chicago, r904.

3 Arch. f. klin. Chir., 1899, 59, p. 175.

4 Lancet, 1907 , 1, p. $106 \mathrm{r}$.

s Arch. Tial. di Anat. e di. Embr., I9п1, 10, p. I03. 
walled lymph channels which do not contain red blood corpuscles. They are as large as the veins but possess thinner walls. In a few places the collections of lymphocytes within them resemble beginning intimal tubercle formation.

The lymph nodes are numerous, and some of them are apparently hyperplastic. Some are deeply stained; others have large germinal centers.

The muscularis and the serosa are intact.

The nearest approach to similar conditions which I have been able to find in the literature of tuberculosis of the stomach is in

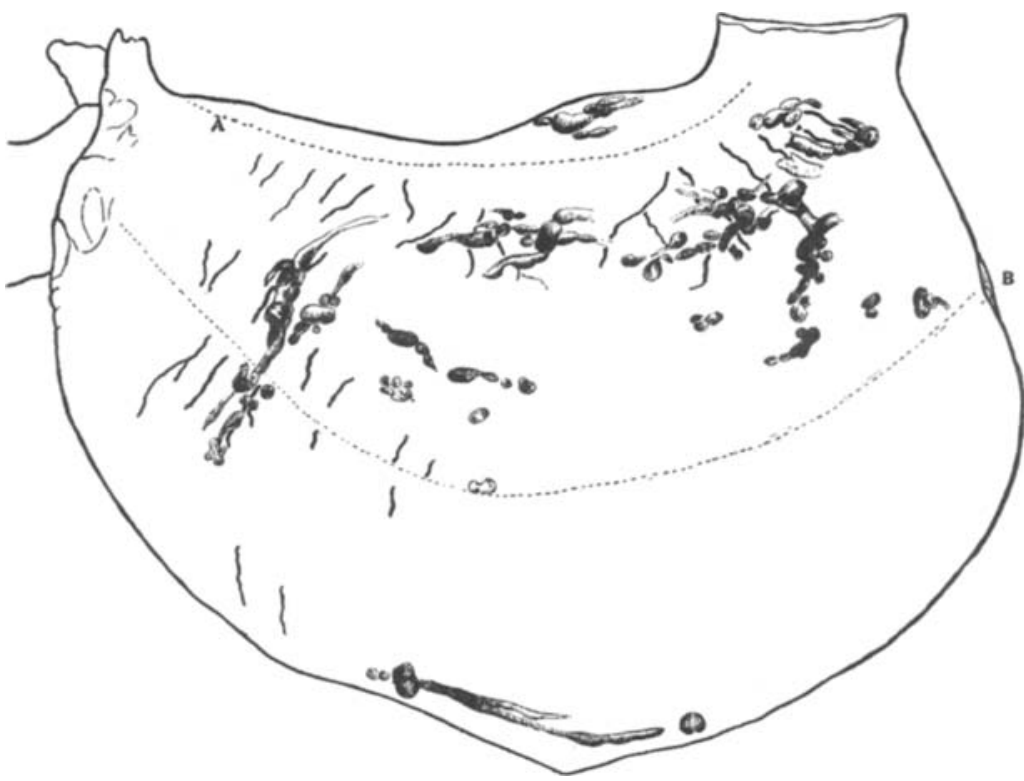

Frc. 2.-The dotted line A represents the location of the lesser curvature, the dotted line $B$, that of the greater curvature, the many small curved lines, the location of the blood vessels. This is onehalf the natural size and the original was made by studying the location of the blood vessels in the Kaiserling (museum) specimen with transmitted light. The general correspondence between the location and direction of the tuberculous lesions and blood vessels is obvious.

the article by Przewoski. He reports five cases of tuberculosis of the stomach, all of the ulcerative type. In his description of the first, in which there were 22 ulcers, he says:

"Around the ulcers the submucosa is distinctly thickened in the form of whitish ridges, two and more centimeters long, extending in all directions or only in some. Over these thickenings of the submucosa the mucosa is less movable and the wall much less transparent. The muscularis under the floor of the ulcers is somewhat thickened and traversed by narrow whitish ridges and some small grayish-white nodules can be seen in several places in the serosa." The microscope discloses "proliferation and leuko-

IVirchow's Arch., 1902, 167, p. 424. 
cytic infiltration along thin-walled spaces accompanying the arteries and veins of the submucosa. Quite often rather broad spaces lined with thickened endothelium can be seen in the center or alongside these rows of leukocytic infiltration. Along these spaces and within their walls the infiltration presents itself here and there in the form of small nodules showing epithelioid cells, giant cells and Koch's bacilli," and the writer concludes: "Hence this is a lymphangitis tuberculosa around the tuberculous ulcers of the stomach. A leukocytic infiltration of this type along the blood and lymph vessels has also produced the whitish lines in the muscularis under the floor of the ulcers."

Of the third case he says: "The only striking feature in this case is the extensive participation of the lymph vessels of the submucosa in the tuberculous inflammation."

In the fourth case in which there are two ulcers, two centimeters apart from each other, situated on the posterior wall, four and three centimeters in diameter, he states: "The submucosa between the ulcers is visibly thickened. Besides this there is a distinct thickening in the form of ridges surrounding the larger ulcer at a distance of one to two and more centimeters."

Przewoski finally compares this type of gastric ulcers with the tuberculous ulcers commonly found in the intestine, and as one of the differential points he mentions the feature which I have singled out from his description, namely the much more marked involvement of the submucosa in the tuberculous inflammation of the stomach. Whether, however, this is a frequent occurrence in the stomach, he admits he is not prepared to say.

In addition to this very definite description of a tuberculous lymphangitis in Przewoski's article we may find, here and there, casual remarks which suggest the existence of a lymphangitis. For example, Schwalbe ${ }^{\mathrm{x}}$ mentions a "moderate round-cell infiltration in the lymph spaces of the tunica muscularis"; Renon and Verliac," "distended and caseous lymphatics especially in the muscularis"; and Ricard and Chevrier "gray and yellowish lines and dots in the floor of the ulcers."

The few statements quoted indicate that tuberculous lymphangitis is at least less commonly noted in the stomach than in the bowel. However, although there is little mention of it in the published accounts of tuberculosis of the stomach, they do contain abundant proof of the rôle played in the morbid anatomy of the lesions by the well-known inherent disposition of this inflammatory process to follow lymph channels. I venture to suggest that the plan of the gastric lymphatic system (see Fig. 3) is, in general, not

\footnotetext{
Iirchow's Arch., 1889, г17, p. 316.

- Bull, et mam. Soc. med. d, hop. de Par., r9o7, 4, p. Iт г.

3 Rev. de chir., т905, 31, p. 74, p. 557, p. 736 .
} 
as familiar to us as that of the intestine, which is a regular and uniform one, that therefore certain features, which in the intestine have been connected with the lymphatics, have not been interpreted or discussed in the same manner. It is conceivable that in descriptions of small ulcers being dispersed here and there or continued in rows from the large ulcers, the distribution of the minor lesions may have followed the course of lymph vessels. In the arrangement of these minute ulcers we can perhaps discover a certain resemblance with the rosary-like extension of tubercles so frequently observed

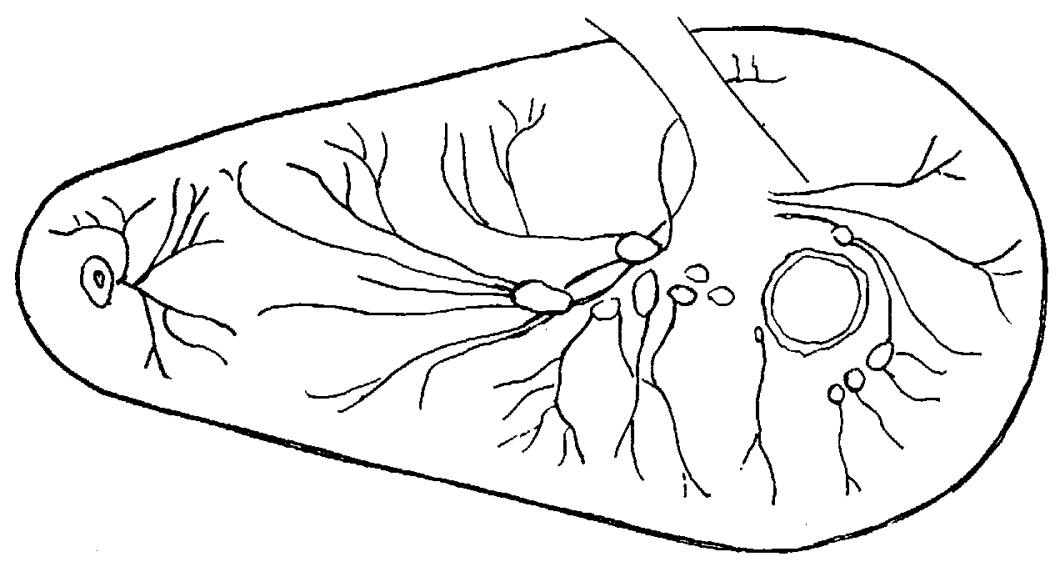

Frc. 3. The lymph glands and lymph vessels about the cardia. From Jamieson and Dobson.

in the intestine. The extensive ulceration described by Eppinger ${ }^{x}$ admits of such an association of the lesions with the lymph channels. In one of his cases there were, on the inner surface, innumerable losses of substance, up to $I .5 \mathrm{~cm}$. diameter, forming whitish rows or ridges along the lesser curvature toward the pylorus, on the posterior and the anterior wall.

In another case there were everywhere losses of substance, arranged in rows, almost throughout the size of a pea. Besides these rows of ulcers innumerable, irregularly distributed ulcers of various sizes were scattered over the walls of the stomach.

Rosset $^{2}$ reports an interesting case. Close below the cardia there is an almost round ulcer, about the size of a penny. Right

* Prag. med. Wchnschr., 188r, 6, p. $50 \mathrm{r}$.

- Ueber einen Fall von iwberkulösem Magengeschwür. Mit besonderer Berucksichligung der Genese. I.D., Freiburg i. B., 1903. 
beside this begins a large, irregularly shaped, more oblong loss of substance whose development from smaller, round ulcers can still be distinctly recognized; it measures about $5.5 \mathrm{~cm}$. in length and $5^{-1} 2 \mathrm{~mm}$. in width. At the lower end of this oblong ulcer, separated from it by a bridge of normal mucosa about eight millimeters broad, a smaller, almost round ulcer, one centimeter in diameter, is found.

Litten's case ${ }^{x}$ presents on the anterior wall of the stomach in the region of the lesser curvature an elliptic ulcer, about 4.2 $\mathrm{cm}$. long and $3.3 \mathrm{~cm}$. broad, the long axis of which corresponds to the direction of the curvature.

Other reports of tuberculosis of the stomach have this in common that the ulcers are oblong and extend along the lesser curvature. May we not assume that the confluence of small ulcers like those in Eppinger's cases along lymph channels, analogous to the familiar processes in the intestine, determined the form and direction of the lesions he described?

A further explanation of the scarcity of reports of tuberculous lymphangitis in the stomach is possibly due to the greater thickness of the wall of the stomach as compared with the intestine and the consequent failure to recognize the relationship to blood vessels so easily perceived in the bowel.

No doubt, too, the microscopic examination which would reveal a lymphangitis is often made simply to confirm the gross anatomic diagnosis.

The rarity of tuberculosis of the stomach as compared with its frequency in the bowel has resulted in studies directed to ascertain the nature of the insusceptibility generally possessed by the stomach and of its vulnerability when involved. Of these studies the following deserve brief mention. Rousseff ${ }^{2}$ found nontuberculous alterations in the lining of the stomach were more frequent when there was an intestinal tuberculosis secondary to one in the lungs than when there was not.

A number of writers $^{3}$ have discussed the relation of lymph

\& Virchow's Arch., 1876, 67, p. 6r5.

- Des rapports qui cxistent entre la tuberculose intestinale et les allirations stomacales dans ia tuberculose puimonaire, Th̀̀se de Genève, 1890 , cited by Zahn, Munchen. med. Wcknschr., 1902, 49, p. 49.

3 Barbacci, Lo Sperimentale, 1890, 65, p. 475; Przewoski, op. cit.; Dobrowolski, Zeigler's Beitr., 1894, 4, p. 43; Wilms, Ceniralbl. f. allg. Palh. u. palh. Anat., I897, 8, p. 783. 
nodes in the mucosa to the tuberculous process. Granted that they may be regarded as the starting-point of the latter, the question still remains, how the tubercle bacilli get to these small masses of lymphoid tissue when the first involvement begins.

There are four possible ways for the tubercle bacillus to enter the gastric mucosa: (I) by direct infection of the mucosa, (2) by a hematogenous invasion, (3) by way of the lymphatics, (4) by direct propagation from a tuberculous focus to the serosa with which it is in close contact. The first mode of infection which has been the subject of a number of thorough investigations will not be discussed here. It cannot absolutely be cxcluded in the instance studied. We have no reason to believe that the mucosa was entirely normal. A degree of gastritis seems to be the rule in the terminal stage of pulmonary tuberculosis and possibly existed here too. Whether there were other predisposing factors for catarrhal conditions, such as alcohol, is unknown. According to Rousseff's observations, already mentioned, that intestinal tuberculosis without exception is always accompanied by distinct structural changes in the gastric mucosa, the presence of four large ulcers in the colon in our case speaks for such changes.

As for the hematogenous mode of invasion, Arloing ${ }^{1}$ believes that it should occupy the first rank in considerations of the. etiology of gastric tuberculosis. He has written exhaustively on the subject and he supports his views by conclusions from considerable experimental work by himself. Wilms ${ }^{2}$ and Simmonds ${ }^{3}$ express the opinion that the miliary hematogenous type of gastric tuberculosis is of much more frequent occurrence than is generally believed.

Before I pass to the third mode of infection which will receive the chief consideration, the last type - that by propagation from a neighboring tuberculous focus to the stomach--may be dismissed briefly. The anatomical conditions of the stomach are such that we must consider cases which seem to speak for such an infection as extreme exceptions. Possibly even these cannot be accepted

- Des ulctrations tuberculeuses de l'estomac (Étude clinique, expérimentale et anatomo-pathologique), Lyon, igo2.

- Centrabli.f. allg. Path. u. path. Anat., 1897,8 , p. 783.

3 Minchen. wed. Wchuschr., I900, 47, p. 317 . 
without reserve, since we see that even a case like that which Chiari ${ }^{\mathrm{x}}$ reports where caseous masses from a much broken down lymph gland extended through a perforating ulcer into the lumen of the stomach admits of another plausible interpretation as we shall see later.

Concerning the third mode of infection - that by way of the lymph channels--very little attention has been given this type throughout the literature on tuberculosis of the stomach. It is in general admitted as a possibility, even a probability, but is rarely discussed.

In textbooks and treatises on tuberculosis, special emphasis is laid on the lymphogenic origin and spread of tuberculosis in general. Orth" writes: "It has long been noticed by observers, that the tubercles in the most diverse organs preferably locate along the lymph vessels, and though it is going too far to say that tuberculosis is a lymphangitis, nevertheless it is certain that a lymphangitis tuberculosa in the small branches belongs to the most frequent changes. They are best seen in the lymph vessels of the bowel, surrounding a tuberculous ulcer of the mucosa, where the subserous lymph vessels are often beset with small gray tubercles for considerable stretches."

Klebs ${ }^{3}$ refers to it as follows: "He who has not convinced himself by personal investigation that tuberculosis is propagated exclusively by way of the lymph channels," etc., and "the infection spreads by continuity, preferably by way of the lymph vessels, and only later by way of the blood vessels." Rindfleisch came to similar conclusions. "From tuberculous ulcers in the intestine rows of nodules follow the course of the lymph vessels, often to the next glands; a lymphangitis tuberculosa this might be called."

It is interesting to note here a statement made by Dürck and Oberndorfer:4 "While the spread of tuberculosis by way of the lymph channels plays a great rôle, it is remarkable, however, that beside the frequent morbid involvement of the lymph glands the lymph vessels themselves are so rarely diseased, so that apart from

. Wien. med. Wchnschr., 1878,24, p. $65^{\circ}$.

- Lehrbuch der speciellen pathologischen Anatomie, Berlin, 1887, 1, p. 275.

3 Virchow's Arch., 1868, 44, p. 242.

tErgebn. der. allg. Path. u. path. Anat, I899, 6, p. 354. 
the tuberculosis of the thoracic duct, described by Benda, cases of lymphangitis tuberculosa belong to the great rarities."

Ruge $^{\mathrm{T}}$ opposes retrograde infection in lymph channels in the following words: "Now, a lymphatic invasion of bacilli into the gastric mucosa would have to take place in a direction opposite to the normally coursing lymph stream. With the non-motility of the tubercle bacillus such a supposition would encounter considerable difficulties. The same is true of the subsidiary hypothesis of an eventual retrograde lymph current in the corresponding vessels." On the other hand the mechanical difficulties to retrograde metastases cannot be great. Cunéo and Delamare ${ }^{2}$ write: "Inasmuch as the lymph glands become actually infected, through embolism, by the intermediary of certain of their afferents, their other afferents can be invaded by retrograde thrombosis and by this mechanism infect the organ, in which they have their origin." Orth ${ }^{3}$ states that "obstruction to the lymph stream with subsequent varicosity of the lymph vessels in the intestine or toward the mesenteric glands is not rare." Perhaps more to the point since it deals with actual conditions in the stomach are the evidences that such a mode of dissemination does take place in tuberculosis of the stomach contained in the report by Rosset ${ }^{4}$ concerning a man, 80 years old, with emphysema, a beginning pulmonary edema, slaty induration of the lung with fibrous nodules. There were caseous bronchial and retroperitoneal lymph glands behind the stomach. Some of the mesenteric glands were as large as a bean and showed a black mass on the cut surface. In several places of the intestine, slight ulcerations, the size of a pinhead, and in one place a somewhat larger, yellow, scarred spot were found. In the stomach there were three tuberculous ulcers; close below the cardia a nearly round ulcer, the size of a penny, in the midst of a markedly injected mucosa; close behind this, a larger, irregular, more oblong ulcer, $5.5 \mathrm{~cm}$. long, $5^{-12} \mathrm{~mm}$. broad, in which the development from smaller round ulcers could still be recognized distinctly; at some distance from its lower end a smaller, nearly round ulcer, one centimeter in diameter, separated from the oblong ulceration by a bridge of normal

1 Beilr. z. Klin. d. Tuberkwlose, I905, 3, p. I91.

z Jour. de l'anat. et physiol, 1900, 36, p. 393.

${ }^{3}$ Op. cit. $\quad$ Op. cit. 
mucosa, measuring about eight millimeters. The rest of the mucosal surface was perfectly normal. Several lymph glands in the neighborhood of the cardia and behind the stomach were enlarged and totally caseated.

As to the origin of these ulcers, Rosset argues as follows: With the very slight extent of the intestinal tuberculosis the possibility of propagation of the infection from the intestine to the stomach may be excluded. A direct infection of the mucous membrane by ingesta containing tubercle bacilli is very improbable; tuberculous ulcers are hardly ever met with in just the pars cardiaca. The complete caseation of the retrogastric lymph glands shows that the tuberculosis in them probably existed longer than the tuberculous ulceration in the stomach. Moreover, not the least manifestations of tuberculosis of a fresh nature were found in the lungs, so that an infection by tubercle bacilli from the lungs cannot be presumed. There remains the supposition that the invasion was from the retrogastric lymph glands. A perforation from without could not be demonstrated macroscopically and the microscopic examination showed simply changes that involved the inner layers and at the highest reached the outer layer of the muscularis; the caseous foci in the submucosa were always separated by healthy normal tissue from the lymph glands situated below the serosa. There was nowhere communication of any of these lymph glands with the foci in the submucosa and muscularis.

Rosset believes therefore that in consequence of the tuberculous process in the retrogastric lymph glands and the anatomical changes resulting from this, there was stasis of the lymph stream, producing a retrograde current which carried the tubercle bacilli into the stomach wall. The primary infection was in the lymph glands at the hilus of the left lung. From them the infection was carried to the retrogastric lymph glands, which are connected with the mediastinal lymph glands by lymph vessels. In these retrogastric glands the tuberculous process brought about changes in the circulatory system whereby the normal outflow of the lymph from the gastric mucosa was hindered and a reversed flow set in. From the resulting necrosis and ulcerations large masses of tuberculous material passed into the stomach and from there into the intestine 
where they produced the small ulcerations which seemed to be quite recent.

Rosset expresses the view that Chiari's case, which I have mentioned, might possibly be considered as a more advanced stage of his own case; that, if his patient had lived longer, caseation would have taken larger dimensions and finally healthy portions which separated the diseased areas would have melted down, until at last in one place, all the layers of the stomach wall would have undergone dissolution in the tuberculous process.

Also the third case in Hamilton' $\mathrm{s}^{\mathrm{T}}$ report is worthy of comparison. "The stomach was adherent to the transverse colon, the pancreas, and to the mass of peripancreatic lymph glands. The serous coat was covered with small and larger caseous tubercles. On the posterior wall and part of the lesser curvature there was an ulcer three centimeters by two centimeters. Directly behind this ulcer was a caseous lymph gland, so closely adherent to the stomach wall that it was impossible to say whether or not it formed the floor of the ulcer. The microscopic examination proved, however, that the process in the stomach was quite independent in its origin, as the still intact muscular wall could be traced along the whole extent of the ulcer between it and the caseous gland."

I have quoted Rosset's case in detail, because his very plausible interpretation of the conditions that were present, and his way of tracing the infection, seem to me in part applicable to the conditions I have studied.

In regard to extension of infections from the thorax into the abdomen and vice versa, Küttner' ${ }^{2}$ studies of the lymphatic system of the diaphragm have demonstrated the presence of numerous perforating lymph vessels from the thorax into the abdominal cavity and vice versa, and what apparently is a retrograde current is in reality normally directed. Such expressions as "retrograde" and "against the current" should be used cautiously, for, as Küttner shows, the determination of the direction of the current in a lymph vessel is often only possible by a direct observation of the injection of this vessel.

The perforating vessels of the diaphragm pass to the anterior and 
posterior mediastinal lymph glands on the one side, and to the parapancreatic, paracoeliac, and paraaortic glands on the other. They are more numerous than those which remain in the corresponding cavity. The lymph vessels of one half of the diaphragm do not communicate with those of the other half; on the other hand there is a very extensive communication between the lymphatic system of the pleural and the peritoneal surface of the same half of the diaphragm. The vessels which carry lymph from the diaphragmatic peritoneum to glands within the abdominal cavity, also take up the perforating channels from the diaphragmatic pleura. All the large lymph trunks of the diaphragm carry both pleural and peritoneal lymph. Such a system, and a perfect arrangement, both mechanical and anatomical, for the movement of the lymph within the layers of the diaphragm make this partitional wall between the two large body cavities particularly suitable to the spread of morbid processes from one to the other. Tendeloo ${ }^{x}$ has emphasized the frequency in tuberculosis of adhesions between one or both lungs and the diaphragm and their importance in favoring the conveyance of infectious material along a seemingly unusual direction; for they result in conditions which necessarily affect the two main factors in the promotion of the diaphragmatic lymph, namely the difference of pressure between the thoracic and the abdominal cavity and the alternating state of contraction of the diaphragmatic musculatum, whereby now suction, now pressure is effected. The perforating lymph vessels of the diaphragm in all probability play an important rôle in metastases of infectious processes from the thoracic into the abdominal cavity, and vice versa.

From these considerations it is easy to understand how, in the case I have presented, infectious material could be carried from the lungs or also from the intestinal ulcers to the para- and praeaortic glands and be deposited there, how from these glands it could find its way into the perigastric glands and how there in the meltingdown process an obstruction could be offered to the normal outflow of the lymph from the stomach with the result of a backward flow from the infected station and importation of tubercle bacilli into 
the stomach, producing there a lymphangitis which designed figures on the stomach wall that in a measure reproduce the picture of the lymphatic system in the corresponding area.

Can a direct infection of the mucosa in this case be excluded? Not absolutely. But I am inclined to believe that the majority of all cases of tuberculosis of the stomach, which clearly are not a.hematogenous infection, have a lymphogenous origin, and that a direct infection of the mucosa should be admitted only in those cases where by complete destruction of the protecting epithelium, as for example, Breus's case, or by some extraordinary coincidence as cancer in the stomach ${ }^{2}$ the mucosa was made an exceptionally favorable culture-ground for the tubercle bacillus.

\section{SUMMARY.}

In studying the case discussed here, and in reading literature on tuberculosis of the stomach, my attention has been directed to two main points, brought to the front by the character of the lesion, which I have endeavored to make clear in this paper: (I) to establish the fact that a tuberculous lymphangitis may occur in the stomach which is not associated with ulcers as the starting-point, but which, in all probability, would ultimately lead to the development of ulcers of the various types known to us from the literature; (2) to give the lymphogenous origin in tuberculosis of the stomach a more positive and a more general consideration than has hitherto been done. Though in my case a direct infection of the gastric mucosa cannot be absolutely excluded, the ensemble of the conditions in this case, the fact of the general tendency of tuberculous processes to spread along lymph channels, and conclusions drawn from the literature on this subject lead me to assume the lymphogenous nature of the infection not only in my case, but in the larger number of cases of tuberculosis of the stomach. 